\title{
Range Start-End Unit Format
}

National Cancer Institute

\section{Source}

National Cancer Institute. Range Start-End Unit Format. NCI Thesaurus. Code C155744.

A format for representation of a range of values along with their associated units where start is the low value of the range and end is the high value, delimited by a vertical bar. 